\title{
Student 'voices' and course development: reading the signs on a distance course in educational technology
}

\author{
Diane Slaouti \\ Faculty of Education, University of Manchester \\ email: diane.slaouti@man.ac.uk
}

Learning occurs through processes of interaction with course components. A major part of the interaction will be between learner and instructional material, but tutors and colearners will form part of the interactions that make up the whole. The nature of these interactions may be both academic and pastoral and in many distance courses are effected through Computer-Mediated Communication (CMC) tools. CMC data represents a record of short-term negotiations and progress but this paper argues that they can find an important place in course evaluation and development procedures. The paper draws on evidence gathered during the delivery and support of a distance course in educational technology for teachers of English as a second language at the University of Manchester. It illustrates how threads of communication provide illuminative evaluation data as they are mapped against events and stages in the lifetime of a course, that is interactions with instructional content, tutors, co-learners. This process of description and interpretation clearly impacts on course development.

\section{Introduction}

Whether in face-to-face or distance mode, courses result not-simply from informed input and pedagogic planning from an academic team but, as Thorpe (1988: 120) maintains from ' $a$ process of interaction between the learner and any materials, staff or facilities associated with the achievement of [those courses]'. This synergy suggests that learners have a pivotal role to play not only in revealing the short-term effectiveness of instructional design and teaching strategies but also in contributing to their long-term development. This is not disputed, as reflected in the place that formal evaluation tools have on most courses. However, many formal course evaluation procedures tend to take a snapshot from the vantage 
point of final impressions. A comment that suggests 'instructional materials were effective' does not tell the real story of how a learner has interacted with those materials along the way. This paper argues for illuminative evaluation (Parlett and Hamilton, 1987) processes as a contributor to the development of distance learning practice in local contexts.

The primary concern of illuminative evaluation is to look at what actually happens (as opposed to what is supposed to happen)' (Rea-Dickins and Germaine, 1992: 26). As such it draws on ethnographic procedures as it is 'an intrinsically descriptive task that resists formalisation [whose] methods rely on the study of people and their activities in their natural environment' (Jones, 1995: 31).

In distance learning contexts, the opportunity to observe, describe and explain activities and interactions (Oliver, 1997) depends very much on a specific model of transaction. Distance courses may be described as having lesser or greater transactional distance (Moore, 1993: 23). If there is greater structure within course materials, there tends to be a greater transactional distance between learner and tutor. The materials designer places great store on the materials themselves in guiding the learner but opportunities for tutors to see how learners are interacting with those materials will be dependent upon provision for dialogue built into the course design.

Dialogue, as exemplified in the potential of computer-mediated communications, not only reduces transactional distance but brings with it greater opportunity for tutors to act as 'participant observers' (Elliott, 1991: 27). It is not, however, simply the elements of dialogue (that is transcripts of computer conferencing events) that reveal the full story. Jones (1998) suggests that analysing transcript alone ignores vital activities which impact on and help to explain events surfaced through dialogue. In terms of course evaluation the descriptions of learner thought and reaction through computer-mediated dialogue can only be interpreted in relation to the other components of the interaction triad: the instructional materials themselves and tutor interventions.

\section{Context of study}

The learners are practising teachers undertaking a distance Masters degree in Educational Technology and English Language Teaching, a modular degree aiming to develop both skills and pedagogic understanding. The programme is supported by the use of computermediated communications (individual email between learner and tutor, course-related discussion lists, and synchronous tutorials using MOOS). The course focused on in this paper develops the participants' abilities to create language learning materials in Asymetrix Toolbook. This study draws on data from a group of sixteen participants based around the world.

\section{Course design}

Participants receive an in-house tutorial written in Toolbook which develops their basic programming skills whilst producing a piece of reading skills courseware. The rationale behind the tutorial is to provide a familiar conceptual framework for language teachers and to provide experience of computer-based learning before the learners design their own materials in response to needs in their current teaching context. This experiential learning approach (Kolb, 1984) is fundamental to the methodology of the degree programme as a whole. It aims to provide for 'reflective conceptualisation and practical experience' (Tait, 
1997: 2), allowing practising teachers to draw on their current knowledge base and their current teaching contexts and develop further their understanding of skill and process. The teachers' understanding of relevant theoretical concepts is guided through supplementary print and Web-based reading. A discussion list encourages support and exchange within the course community. The following can thus represent the interactions within the course:

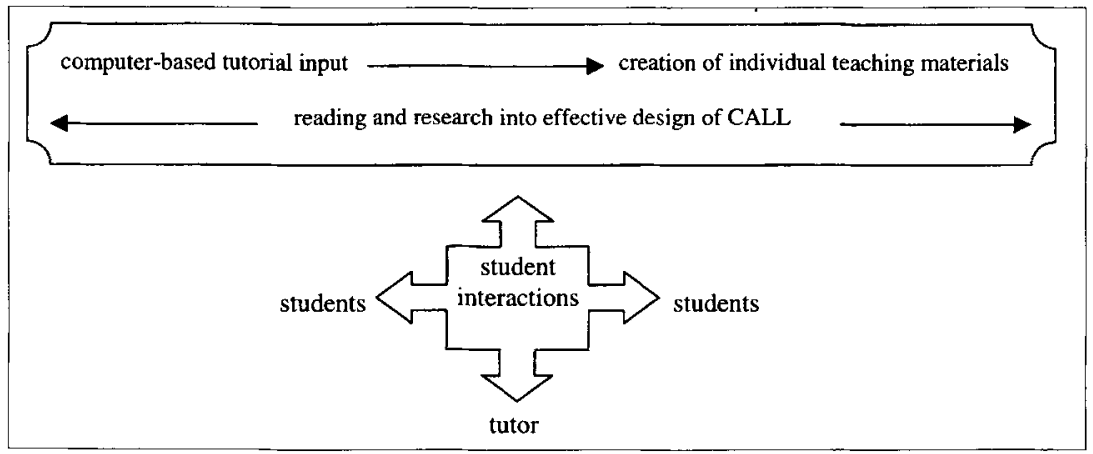

Figure 1: A conceptual map of interactions with course.

\section{Method}

Computer-mediated communications evidently provide a source of ongoing data. The messages sent to the discussion list and to individual tutors are archived and these were looked at in terms of threads involving various combinations of student-tutor, student-student-tutor interactions. As argued previously, however, threads of exchange are not to be read in isolation from other events that go to make up the whole of a course. They form a partial picture that can be described but only interpreted in relation to a larger scenario. A thread can, therefore, be analysed in terms of learner message, tutor intervention, point in course (relevant to design of instructional material or recognizant of a stage in knowledge construction).

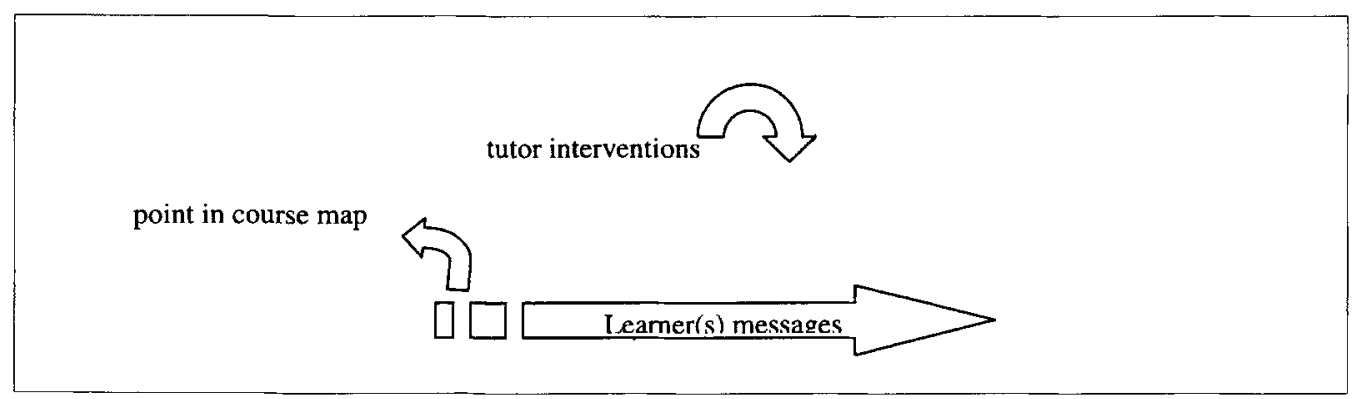

Figure 2: Relationship between tutor interventions, students and point in course map.

\section{Findings}

I have drawn on a number of findings from the data that illustrate the process of illumination. I will focus on analyses that provide insight into the design of the course and its materials, tutor interventions and the role and expectations of the course community. 


\section{Critical moments in the lifetime of a course}

\section{Situating learning}

This course requires learners to transfer learning through the course materials (CBT and supported reading) to their own contexts, to begin to situate it for themselves. This process of transfer is critical to successful learning. Garrison and Shale (1990: 37) suggest 'the most important aspect of the educational transaction is what happens after the student has been presented with the content. In distance education this presents a special problem. With the teacher and student being separated, greater effort is required to understand the communication process so vital to supporting the learning activity.'

Many of the threads examined indicated degrees of uncertainty in that transfer.

\section{Hi Gary}

I've been through the tutorial and think it was great. But now I am sitting in front of a blank Toolbook page and I just don't know where to begin. It seemed so easy as I was working through the tutorial - has anyone else said they've got similar concerns?

[extract 1]

\section{Hi Diane}

I find the CELSE tutorial 10 times better than the one from Toolbook itself. However, I have got stuck on the button drawing stage and thus am making zero progress. I select the button I want from the palette, the cross symbol appears and I position the cross where I want the button to appear and then (regardless of which mouse button I click/double click) nothing happens! I've done this numerous times. Am I never going to get past the starting line?

[extract 2]

Similar messages were received from over half of the course participants. Figure 3 describes the pertinent components of this interpretation:

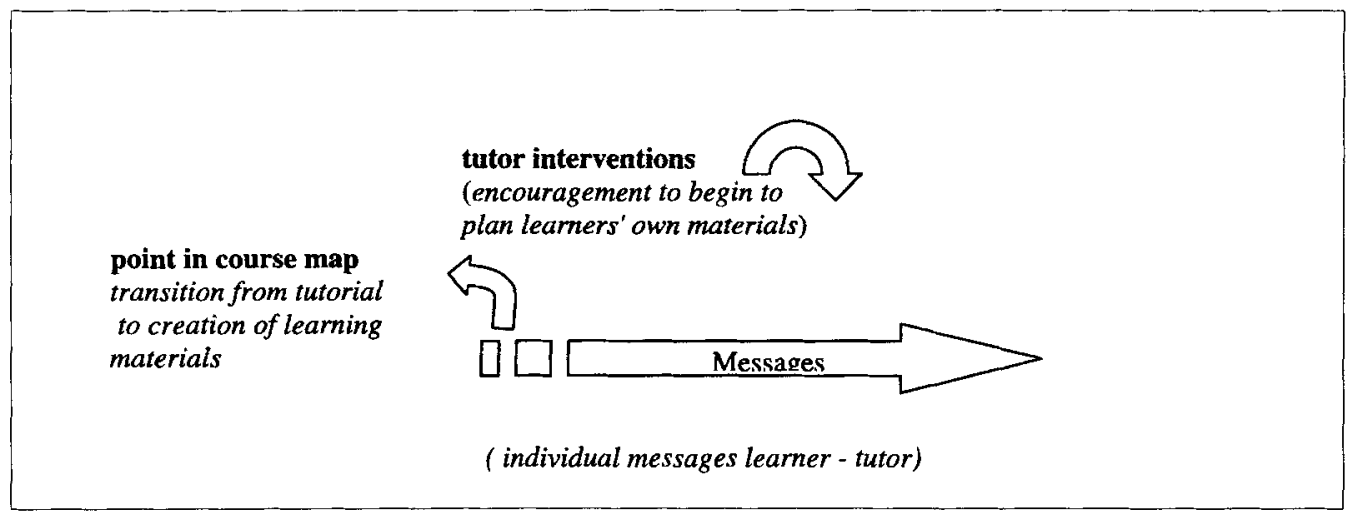

Figure 3: Example of tutor/student-situated intervention.

The messages were on the whole not critical of the course content. Indeed formal, retrospective evaluation processes also elicited very positive opinions on the whole. What these messages do reveal is a critical moment in the lifetime of this course. It is interesting to note that most of such threads happened away from the discussion list, that is they were 
not shared moments of coming to know but declarations of uncertainty between student and tutor. They were, however, threads that were being replicated in several private exchanges. Drawing on Salmon's research into online moderation (1998) it was clear that we were straddling a moment in which information-sharing, a potential support to members of the group as they began to transfer their understanding to their own contexts, would benefit from clearer encouragement. The following indicates a tutor intervention that became an overt strategy to help to develop information-sharing and co-operative working:

\section{Hi all}

John emailed me asking for help in where to start with his Toolbook project and I thought as I was typing, maybe my response might help others who hadn't yet got an idea formulated. The best place to start is with what you as teachers know about sound teaching approaches.

[extract 3]

This message continues with a personal example of how the tutor developed her own piece of material for a group of teacher trainees. The fact that the reply was turned back to the list drew further descriptions of what people had in mind for their projects.

\section{Impact of assessment}

On the whole requests for help with problems in the early stages of the course may have exhibited frustration ('Am I never going to get past the starting line?') but generally implied a sense of trust and belief that support would be eventually effective. Learners were often apologetic about not being able to resolve a problem despite sequences of messages trying to guide them to a resolution ('I'm really sorry but I still can't yet see how this can work'). However, the following illustrates a different type of message:

Since receiving your message about runtime, I spent the best part of a day trying to work out what to do. I agree with Ed about people who are not too skilled encountering problems - I am definitely one of them. The point I am trying to make is an awful lot of time is being wasted on things that seem very easy to the skilled computer users/experienced users of Toolbook. As deadlines are looming, panic takes over. [extract 4]

Figure 4 represents the relevant descriptions that help to interpret this message.

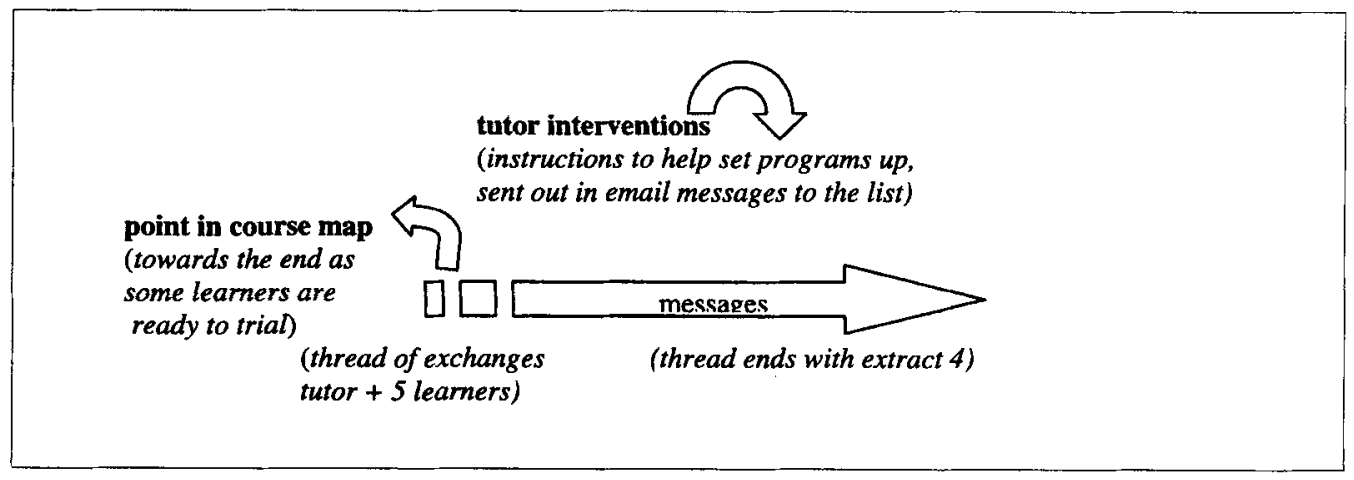

Figure 4: Interpretation of the message. 
This message culminates a thread to which this particular student had until now not contributed. It happened towards the end of the course, as some students were ready to package their programs. The message refers to another student's seemingly similar lament (Ed) but this was not in fact part of this current thread.

This message, therefore, needs to be situated in relation to all of these factors. It is close to a pending deadline (assignment submission); it provides some insight into overall pacing and scaffolding for different course participants. Learners who were able to develop on their own took best advantage of the course as it stood. They also began to dominate the discussion list, driving forward a focus on relatively complex issues. This engendered a feeling of 'second classness' in this respondent (explored below) and pointed to a gap in the course provision.

However, this thread, whilst indicating a need for some further reflection on how we provide better support for some of the operational procedures related to developing courseware, engendered a further thread which provided pleasing signs of how the community had developed. Advice on how the course might be developed for future generations of students arose out of this description of short-term need:

A general problem with the user manuals and the online help is that they describe the functions of toolbook, but what most of us need is a 'how to achieve certain learning tasks' manual (I find wading through the manuals very disheartening at times.) The most effective help I've received is via the email list. It might be useful to develop a troubleshooter manual out of this for future generations of md319ers as they are bound to experience the same problems as we have.

[extract 5]

This suggestion was taken further in the form of exemplar tasks and scripts in the course revision.

\section{Strategic lessons in cognitive style and tutor intervention}

Sparkes (1993: 139) discusses the implications of trying to match teaching methods to educational aims and refers to the work of Pask (1976) in considering the need to take account of variety of cognitive approach to learning within individual learners. Pask's work describes learners as 'holist' or 'serialist' in the way in which they process information; as 'verbalizers' and 'visualizers' in their representation of information in memory. Sadler-Smith (1996), referring to these dimensions following the work of Witkin, Moore, Goodenough and Cox (1977) as 'wholist' and 'analytical' and 'verbalizer' and 'imager,' suggests that 'one may anticipate beneficial effects on learning performance if the mode and structure of the presentation of information respectively compensate for, and are matched to, the learners' cognitive styles' (p. 189). However, the exact nature of such provision will vary from course to course. In the course under study, a number of threads would appear to provide some direction as to needs that might be satisfied in course development procedures.

\section{Did instructional design satisfy the wholist and analytical learner?}

The instruction in this course is carried largely in the early stages by the computer-based tutorial. It was clear that whilst the tutorial was well received by many in the first-year group, there was evidence that this did not suit all. At the time students were reticent to say 
it was the mode of learning itself. Perhaps they did not know exactly why they found it difficult. In a revised dispatch of the course, the students were provided with print materials covering much the same ground as the computer-based tutorial. One student, who had actually never finished the original course, restarted.

Dear Diane

I'm well into my md319 and must say your Toolbook unit was really helpful. Just what I needed I suppose. I not only managed to do it but actually started to be able to understand and correct mistakes I had made last time round. So, thanks to you for an extremely user-friendly design of the material for us. I wonder how other people got on with the tutorial? Am I the only one not to have managed?

[extract 6]

When quizzed further:

I don't know what it was - I never really got a sense of where I was going. I know the tutorial was actually very thorough but I suppose I couldn't see what the final thing was supposed to look like - I hadn't planned what I was going to do myself and I didn't have an example of the finished program like you have now. I also find I work much better having a paper-based booklet to refer to as I'm constructing the program too. [extract 7]

This evidently dashed our hopes of providing a computer-based learning experience as part of the learning process but this aim had clearly been to the detriment of this particular learner. More wholist needs evident in the further message were attended to quite easily. The reading programme that was to be reconstructed was first presented in the revised material as an evaluation task encouraging reflection on its pedagogic approach. In essence this now formed an advance organizer providing a sense of global direction (McLoughlin, 1999).

\section{Did the instructional materials satisfy the verbalizer and the imager?}

The hands-on tutorial breaks down the process of designing a specific piece of courseware and guides the user through a combination of visual screenshots and text instruction. This would, therefore, appear to provide for different representations of information and this drew no explicit comment. As learners move on to construct their own materials, support is provided via email, that is in text format. Thus tutor support was a focus of analysis for us as we sought to develop our own understanding of online teaching and learning.

There were clear examples of students responding to different types of support within the email mode. Referring back to extract 2 , this message began a thread of six messages during which the learner's problem was not resolved. The drawing of navigational buttons within the authoring tool is a prerequisite of program design and the frustration evident in this first message developed. The tutor then tried a different strategy. Using Lotus Screencam, which enables the capture of all moves on a user's computer screen in a visual media file, the process of creating and manipulating the desired buttons was recorded, saved as an exe file and emailed as an attachment to the student. This is the message that followed: 
The software is excellent - I could see straight away what I had to do and it worked. Thanks! My next problem is related to syntax but I'll have a go at solving the problem myself first. I think I may have created too many pages.

[extract 8]

It is interesting that the learner clearly responded so immediately to the visual support, but also the second idea suggests that, having been helped over this block, the learner shows signs of being determined to tackle a new problem by himself. Similar declarations of increased autonomy are evident from another student:

Went back for another look at the Screencam and have worked out the answers to both my questions that I have asked you in my last email! I'd missed 'end' off the script and then realised that to reset the page you just have to go to the next page!

[extract 9]

This message examined against other interventions from the tutor provides further reinforcement to the evidence of different cognitive styles. The problem referred to is in fact a textual one, that is the missing off of the word 'end' from the programming script. The relevant script had been emailed in full in text form but the student had not transferred this correctly. In the Screencam version, the student watches as the tutor 'types in' the script on the screen in front of them. The student is therefore visually processing emerging text as it is being written dynamically. Another student, however, was less than happy with the Screencam type approach.

I hate those demo things you get with computer software and I think that's why I didn't like Toolbook's own showme type tutorial. I just can't absorb it like that. [extract 10]

\section{Reviewing expectations of community}

Figure 1 makes clear that there was an expectation of computer-mediated communications providing for a sense of community as well as for individual support from tutors to students. The notion of networked community in support of learning is well documented (e.g. Harasim, 1989; Salmon, 1998). However, two critical issues arose through analysis of the data relating to this course: the shifting nature of moderator roles to enable the building of a supportive and interactive community and the potential of that community to act not only as support but also threat to its members.

\section{Building community}

Messages during the running of this course bore clear evidence of the supportive nature of successful community development but this needed working at. In the early threads the messages may have been posted to the list, but the threads consist of student-tutor exchanges in fairly rapid succession. This was of course received very positively by students but it led to a dependence on tutor response and support. On occasions when response was not so immediate for whatever reasion, messages such as the following were evidenced:

It appears that $\mathrm{T}$ is too busy marking assignments to deal with problems - even from his \#1 fan. Is there anyone else who can help? I especially need help deleting unwanted backgrounds and pages. Thanks in advance.

[extract 12] 
This message was in fact quickly followed by a response from one of the 'quieter' group members:

I think I may be able to help. I had exactly the same problem when I started out - I was clicking on New Background rather than New Page every time I want to add a page! You can get rid of them quite easily by going to the edit menu and click on select page then again on the edit menu click delete selection. Hope this helps.

[extract 13]

This thread revealed that we had not nurtured terribly successfully the potential of the community to provide support. Graddol (1989: 238) talks of the 'burden of social maintenance' required in CMC contexts, to develop a sense of belonging and mutual dependence. In the second run of the course, we made explicit the advantages of belonging to the community of growing expertise and consciously allowed time and space for other contributions in response to queries.

\section{Community as threat}

Students reported being generally very positive about the role of the discussion list in support of their learning. Contributions to the list, however, varied over time in both frequency from individual members and in moments chosen to post.

I hope you don't mind this direct to you? I'm a bit worried about my program design. I'm only using text in my business program. They do their actual work in Word. Maybe I should be putting everything into Toolbook? It's not very technical really. Maybe I should be using more media and getting them to do more complex tasks?

[extract 14]

The opening line of this message is key to this student's sense of insecurity at this moment during the course. This message followed a number of outlines of project (informationsharing) in response to extract 3 . This is clearly prompted by a comparison between the student's own plans and those she has read about. It also points to the sense of exposure that can be attributed to online contributions that once committed via the send button are not as ephemeral as spoken interactions (Grint, 1989). This sense of exposure can be evident at different points in a course and as tutors we are aware of the sensitivities of students who may wish to contribute or may at times prefer to lurk and communicate in less public ways.

\section{Illuminative evaluation: a tutor's perspective}

There is no doubt that the process of analysis and reflection illustrated in this paper benefits from the growing experience of the tutor. In my own early days of distance teaching, there was a tendency to react rather quickly to isolated comment that suggested something was not quite right with the course content or delivery, that is I failed to situate this within a larger picture of interaction. A problem highlighted by one learner was often interpreted as a problem with the course itself rather than as an issue that might have had more significant relevance to a specific point in time or in relation to a specific learner need. Experience has shown how important that bigger picture is, and I would suggest that distance course evaluation procedures should take cognizance of illuminative procedures at their design stage. 
There is also no doubt that the fact that there was more than one tutor involved facilitated the reflection and interpretation. Again dialogue is a key factor in this process. However, illuminative evaluation is a tool of the reflective practitioner (Elliott, 1991). The success of interactions between learners, tutors and course content is dependent on constant observation and review, no matter whether this is in face-to-face or distance contexts. Moreover, I would suggest that this contributes, as does reflective practice generally, to the professional development of the distance tutor. This analysis demonstrates that computermediated communications not only establish contact between the various people involved in a course but, equally importantly, provide the feedback that ensures the development of the skills and understanding of the distance tutor.

\section{Conclusion}

Jones (1998: 32) acknowledges a potential tension between 'ethnographic stress on description and the prescriptive requirements of evaluation'. However, the purpose of evaluation is to 'see' how learners are interacting with the course provided and this act of 'seeing' is a dynamic one, possible only in procedures which capture the process rather than the end product. Ethnographic description becomes illuminative evaluation in the process of interpretation. That interpretation, as argued in this paper, relies on a triangulation of views of the essential interactions within a course, in this case between learner and instructional material, between learner(s) and tutors. It is through CMC that these interactions are visible and provide tangible and meaningful contributions to course planning.

\section{References}

Elliott, J. (1991), Action Research for Educational Change, Milton Keynes: Open University.

Garrison, D. and Shale, D. (1990), Education at a Distance: From Issues to Practice, Malabar: Krieger.

Graddol, D. (1989), 'Some CMC discourse properties and their educational significance', in R. Mason and A. Kaye (eds.), Mindweave: Communications, Computers and Distance Education, Oxford: Pergamon Press, 236-41, available online at http://wwwicdl.open.ac.uk/mindweave/mindweave.html.

Grint, K. (1989), 'Accounting for failure: participation and non-participation in CMC', in R. Mason and A. Kaye (eds.), Mindweave: Communications, Computers and Distance Education, Oxford: Pergamon Press, 189-92, available online at http://wwwicdl.open.ac.uk/mindweave/mindweave.html.

Harasim, L. (1989), 'On-line education: a new domain', in R. Mason and A. Kaye (eds.), Mindweave: Communications, Computers and Distance Education, Oxford: Pergamon Press,

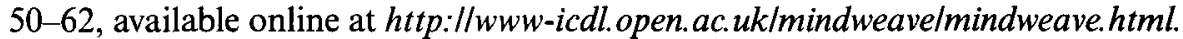

Harasim, L. (1990), Online Education: Perspectives on a New Environment, New York: Praeger Publishers.

Jones, C. (1998), 'Evaluating a collaborative online learning environment', Active Learning, 9, available online at http://www.ilt.ac.uk/resources/publications/al_archive/issue9/al9.htm. 
Jones, C., Asensio, M. and Goodyear, P. (2000), 'Networked learning in higher education: practitioners' perspectives', Alt-J, 8 (2), 18-28.

Kolb, D. A. (1984), Experiential Learning, Englewood Cliffs, NJ: Prentice Hall.

McLoughlin, C. (1999), 'The implications of the research literature on learning styles for the design of instructional material', Australian Journal of Educational Technology, 15 (3), 222-41, available online at http://www. cleo.murdoch.edu.aulajet/ajet 15/mcloughlin.html [last accessed 29.10.00]

Moore, M. (1993), 'Theory of transactional distance', in D. Keegan (ed.), Theoretical Principles of Distance Education, London: Routledge.

Oliver, M. (1997), 'A framework for evaluating the use of educational technology', BP ELT report No. 1, University of North London, available online at http://www.unl.ac.uk/tltclelt/elt1.htm, [last accessed 30.10.00].

Parlett, M. and Hamilton, D. (1987), 'Evaluation as illumination: a new approach to the study of innovatory programmes', in R. Murphy and H. Torrance (eds.), Evaluating Education: Issues and Methods, London: Harper Row Ltd.

Pask, G. (1976), 'Styles and strategies of learning', British Journal of Educational Psychology, 46, 128-48.

Rea-Dickins, P. and Germaine, K. (1992), Evaluation, Oxford: Oxford University Press.

Sadler-Smith, E. (1996), 'Learning styles and instructional design', Innovations in Education and Training International, 33 (4), 185-93.

Salmon, G. (1998), 'Developing learning through effective online moderation', Active Learning, 9, available online at http://www.ilt.ac.uk/resources/publications/al_archive/issue9/ al9.htm.

Sparkes, J. (1993), 'Matching teaching methods to educational aims in distance education', in D. Keegan (ed.), Theoretical Principles of Distance Education, London: Routledge.

Tait, B. (1997), 'Constructive Internet-based learning', Active Learning, 7 [online http://www.ilt.ac.uk/public/ctilActiveLearning/al7.html].

Thorpe, M. (1988), Evaluating Open and Distance Learning, Harlow: Longman.

Warschauer, M., Turbee, L. and Roberts, B. (1996), 'Computer learning networks and student empowerment', System, 24 (1), 1-14.

Witkin, H., Moore, C. A., Goodenough, D. R. and Cox, P. W. (1977), 'Field dependent and field independent cognitive styles and their educational implications', Review of Educational Research, 47, 1-64. 